\title{
Unilateral zygomaticomaxillary complex fracture Shunmugavelu $K$
}

A 25 year old male was attended in the Department of Dentistry and Faciomaxillary Surgery, with a presentation of oedema, abrasion and lacerations in relation to the left side of the face. Case history elucidated the etiology as two wheeler accident. No comorbidities were observed. Patient was conscious, oriented and afebrile. Vitals stable. Clinical examination revealed oedema, warmth, tenderness on palpation, occlusion stable, three finger breadth mouth opening, satsifactory lateral temporomandibular joint movements, step-like deformity, satisfactory extraocular movements, subconjunctival hemorrhage, periorbital oedema and satisfactory visual examination. Three dimensional computed tomography (3D facial CT) revealed minimally displaced fracture in relation to left zygomaticomaxillary complex (Fig 1, Fig 2, Fig 3).
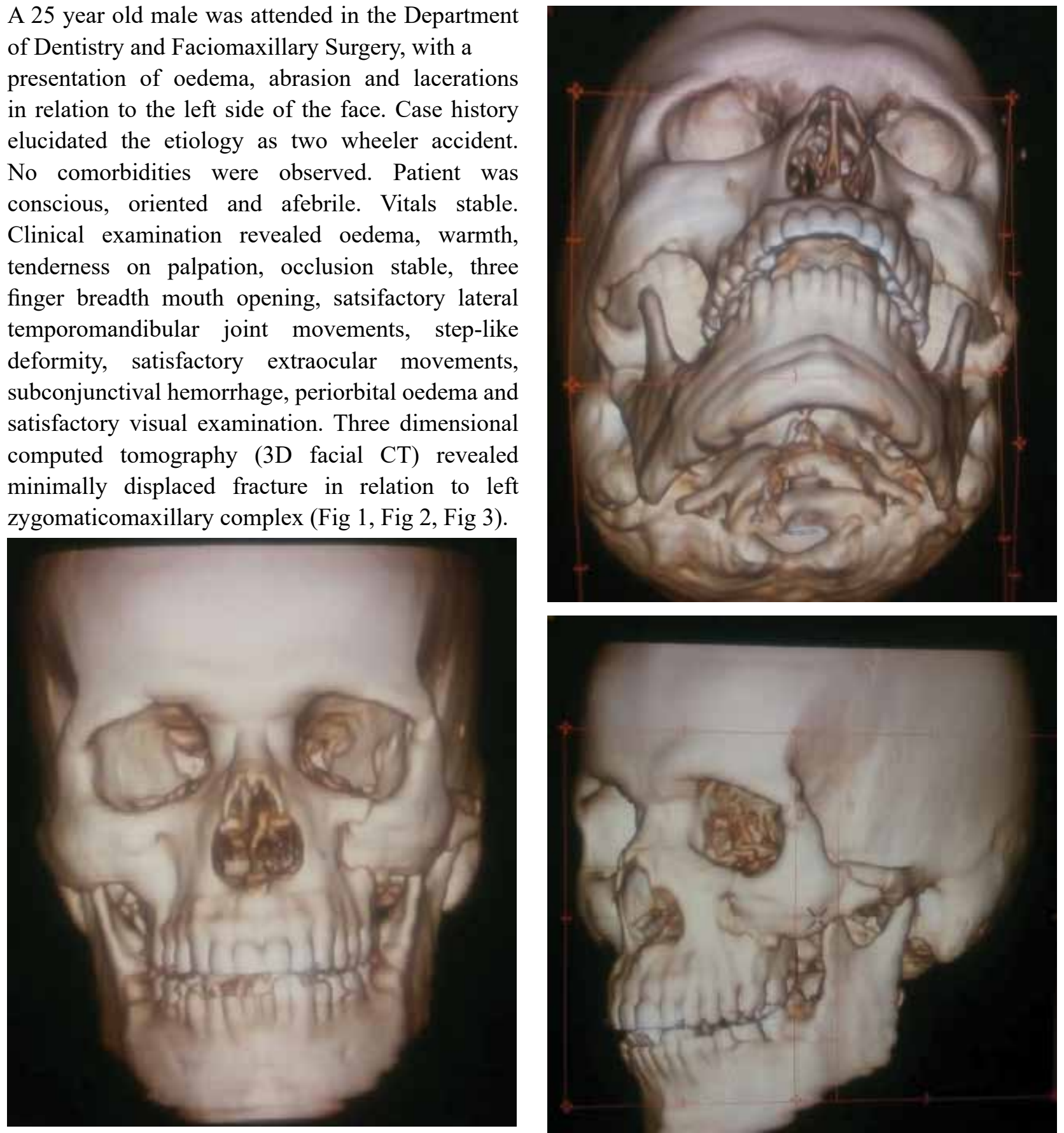

Based on the functional movements, occlusion and mouth opening, the treatment plan was of conservative management. The patient was reviewed after a few months favouring successful outcome.

Correspondence to: Dr. Karthik Shunmugavelu, Consultant Dental Surgeon, Mercy Multispeciality Dental Centre, 8/27, Parvathipuram $1^{\text {st }}$ Street, Thiruneermalai Main Road, Chrompet, Chennai - 600044 Tamilnadu, India. Email: drkarthiks1981@gmail.com, Tamilnadu, India 